\title{
LA DECORACIÓN ESCULTÓRICA DE LA VILLA ROMANA DE "EL RUEDO" (ALMEDINILLA，CÓRDOBA)
}

\author{
Desiderio VAQUERIZO GIL \\ Profesor Titular de Arqueología \\ Universidad de Córdoba
}

El proceso seguido hasta la casi total excavación del complejo arqueológico (villa y necrópolis) conocido como El Ruedo ha sido ya reseñado en algunos de nuestros trabajos anteriores (1). En ellos, el lector puede obtener una visión somera de la gran cantidad de dificultades -especialmente de carácter administrativo- que lo han acompañado y, al mismo tiempo,-disponer de una breve reseña acerca del espectro cronológico que abarca el yacimiento.

Para no pecar de reiterativos, queremos recordar tan sólo que se trata de una villa de planta helenística, estructurada en principio en torno a un patio porticado que es levantado en torno al segundo cuarto del siglo I d.C, y que se mantiene ocupada al menos hasta mediados o fines del siglo $\mathrm{V}$ d.C.

A lo largo de este largo periodo -que abarca en realidad toda la época imperial romana- el conjunto "urbano-rústico" de El Ruedo atraviesa muy diversas vicisitudes, que parecen plasmarse en un floruit a lo largo de los siglos I y II d.C, una recesión -tal vez incluso un abandono parcial- a lo largo del siglo III y una gran restructuración arquitectónica a fines de esta última centuria o comienzos de la siguiente. De esta manera, la mayor parte de las estructuras conservadas se adscriben cronológicamente a este último momento, al tiempo que la villa presenta en casi su totalidad una estratigrafía muy simple, compuesta si bien en algunas estancias se observan reocupaciones posteriores- por un único nivel arqueológico que responde al hundimiento de las estructuras en uso a lo largo de los siglos IV y V d.C.

(1) VAQUERIZO GIL, D (1989 a), "Villa y necrópolis romanas de 'El Ruedo' (Almedinilla, Córdoba). Memoria provisional de los trabajos de seguimiento y excavación de urgencia desarrollados entre los meses de diciembre de 1989 -julio de 1989"', Noticiario Arqueológico de Andalucía 1989, Sevilla (en prensa).

(1989b),' 'Novedades de arqueología en Almedinilla (Córdoba)", / Encuentros de historia local. La Subbética, Lucera - Cabra - Priego de Córdoba, octubre de 1989, Córdoba, 1990, pp. 61-79.

(1990), "E1 Ruedo. Una villa excepcional en Córdoba", revista de Arqueología. Año XI, Ne 107, Marzo 1990, pp. $36^{\wedge} 8$. 
A este momento pertenecen, por tanto, la mayoría de los mosaicos y pinturas murales que decoran la villa, la necrópolis de inhumación anexa, que, según parece, penetra en época visigoda, y gran parte de los alzados conservados. Todos estos aspectos son en la actualidad objeto de estudio pormenorizado a cargo de D. Rafael Hidalgo Prieto, Dña. Silvia Carmona Berenguer y D. José R. Carrillo Díaz-Pinés, quienes realizan sobre ellos sus Memorias de Licenciatura, acerca de las cuales nos presentan un concienzudo avance en este mismo volumen.

No obstante, la villa de El Ruedo ha proporcionado resultados de carácter espectacular también en lo relativo a otros órdenes y, en este sentido, uno de los más destacados es sin lugar a dudas la serie de esculturas de que se sirvió para la decoración de sus patios, estanques, fuentes y estancias principales. Son esculturas que hemos podido recuperar en todos los casos entre los escombros que constituyen el nivel de los siglos IV y V d.C. pero que, por sus características estilísticas, deben ser remontadas en buena parte a comienzos de la época imperial, lo que nos está indicando una clara pervivencia de las mismas y, consiguientemente, un aprecio indudable de su valor artístico, aún cuando hubieran perdido el sentido ideológico que pudo motivar su instalación primigenia.

Estas esculturas merecen sin duda un estudio detenido, por lo que nuestra intención en estas líneas reside tan sólo en darlas a conocer. Pretendemos, por tanto, realizar un mero catálogo que permita a la investigación el acercamiento a un conjunto de tanta entidad, pero debemos insistir en que su interpretación en el más amplio sentido, ajustada a los propios programas iconográficos en que se enmarcan, así como en relación con la problemática cultural y cronológica de la villa en que fueron utilizadas, queda pendiente de un estudio en profundidad que, lógicamente, formará cuerpo con el resto de trabajos reseñados, hasta dar lugar a una publicación conjunta (2).

Describiremos cada pieza indicando tan sólo la estancia en que fue recuperada (la planta puede ser consultada en el articuló referente a la técnica ediliciá recogido en este mismo volumen) y su número de inventario -en ocasiones de carácter múltiple, dado que la escultura ha sido conformada por nosotros de manera definitiva mediante varios fragmentos inventariados con anterioridad-. Finalmente, incluimos fotografía tan sólo de aquéllas que, a nuestro juicio, reúnen mayor interés. Por este motivo, y en aras de la brevedad, prescindimos de buena parte de los fragmentos.

Prácticamente toda la escultura aparece fragmentada de antiguo, proceso que, a nuestro juicio, obedeció a una acción perfectamente calculada por visitantes ajenos a la villa, tal vez en época visigoda. Por otra parte, alguna de ella -en concreto Attis, Andrómeda, las Hermae, etc.- fue recuperada en el interior del pequeño estanque central biabsidado, a donde, al parecer, fueron arrojadas varias piezas, que quedaron depositadas junto al ábside Norte. De todas maneras, es preciso reseñar que, independientemente de los destrozos ocasionados en este momento, las esculturas se han visto sometidas con posterioridad a remociones indeterminadas, como parece demostrar el hallazgo de fragmentos de una misma pieza en distintas estancias. Este hecho podría resultar evidente en el caso de la base del grupo que

(2) Además de los estudios a que hemos hechos alusión más arriba, se van a realizar dos Memorias de licenciatura más, aún pendientes de asignación definitiva, sobre los temas: "Materiales cerámicos de la villa de El Ruedo (Almcdinilla, Córdoba)" y "Toréutica y artes menores en la villa de El Ruedo (Almedinilla, Córdoba)". Con todo ello pretendemos crear un corpus global que abarque todos los aspectos arqueológicos relacionados con este complejo rural y que permita, al final del proceso, una publicación monográfica que pueda resultar clarificadora acerca de este tipo de asentamientos romanos en España. 
representa la leyenda de Perseo y Andrómeda, recuperada en la Estancia XVII. Sin embargo, no hay que descartar la posibilidad de que tras la destrucción provocada del mismo, la imagen de Andrómeda fuera transportada hasta el patio para ser arrojada al estanque. Ignoramos qué pudo suceder con la figura de Perseo, así como con las cabezas de ambos.

Por último, tanto en lo que se refiere a los mármoles como a los propios bronces, en tanto no se practiquen los análisis estilísticos y de muestras pertinentes, no creemos prudente pronunciarnos acerca de su origen. No obstante -y aunque en el caso del Hypnos creemos que no existe duda de que se trata de una pieza importada- en lo que atañe a los mármoles, si bien los bloques originales pudieron ser importados, no hay que descartar la posibilidad de que su labra tuviera lugar en algún taller local, situado tal vez en Corduba o en alguna de las ciudades romanas de importancia más próximas (3).

\section{Fragmento de placa marmórea.}

Estancia XI / Peristilo N / 1.

Mármol blanco, con concreciones.

Alt: $17 \mathrm{~cm}$; Anch: $22 \mathrm{~cm}$; Gros. medio de la zona en relieve: $6-7 \mathrm{~cm}$.

Decorada en altorrelieve con un motivo irreconocible dotado de tres apéndices diferenciados de un cuerpo serpentiforme que presentan una hendidura central. Va enmarcado bajo una moldura con tres filetes, el inferior de tendencia semicircular, con $2^{\prime} 2 \mathrm{~cm}$. de anchura, y por una pilastra rectangular con tres toros y dos anchas escocias que remata el relieve por la izquierda. Profundidad: $815 \mathrm{~cm}$.

\section{Cabeza de rasgos juveniles (Lám. 1,3).}

Estancia IX / Sector N / 3.

Mármol blanco, con algunas concreciones.

Alt: 19 '5 cm; Gros. máx. a la altura de la frente: $12 \mathrm{~cm}$; Gros. a la altura de la nariz: 9 $\mathrm{cm}$; Gros. del cuello: $5 \mathrm{~cm}$.

Se halla cortada a la mitad, a la manera de una herma, con la parte posterior sin desbastar, con ligeras acanaladuras para facilitar su ensamblaje en la argamasa. Fractura que afecta a la nariz y parcialmente a la boca; ligeros desperfectos también en barbilla, frente, ceja y ojo derecho, así como en la sien de este mismo lado. La zona inferior del cuello presenta un corte de tendencia triangular, posiblemente para ser acoplado a un busto, lo que nos lleva a suponer que pudiera haber sido tallada originalmente en bulto redondo y más tarde seccionada.

La cabeza adopta una postura graciosamente curvada hacia la derecha, formando arco. Las orejas apenas han sido trabajadas. El pelo, tallado de manera bastante somera cae en mechones hacia adelante hasta la altura de las orejas.

Se trata, en definitiva, del retrato de un personaje de época julio-claudia.

(3) Comunicación personal de P. Rodríguez Oliva, a quien agradecemos la sugerencia. No quisiéramos desaprovechar la ocasión, además, para mostrar nuestro agradecimiento, por su inestimable ayuda en la elaboración de este artículo, a P. León Alonso y a J. Beltrán Fortes.

Gracias finalmente a las Delegaciones Provinciales de Cultura y Obras Públicas, al limo. Ayuntamiento de Almedinilla y a todas aquellas personas que han colaborado en la excavación, en especial a los miembros de nuestro equipo. 
3. Tres grandes fragmentos de labrum o fuente de mármol (Lám. II, 4).

Estancia IX / Ángulo NO / 4.

Mármol blanco-amarillento, con concreciones.

Diám. aprox. de la boca: 26'4 cm.; Diám. aprox. de la base: 15'4 cm; Alt: 13'2 cm; Gros. medio de la pared: 3'4/4'1 cm.

Fueron hallados en el interior del gran estanque rectangular.

Superficie exterior apenas trabajada, con aspecto muy rugoso. Superficie interior alisada. Base plana. Constaba al menos de dos canales vertedores dispuestos a la manera de asas o pico de forma trapezoidal. Anch. máxima de éste: 3'2 cm.; Long. del mismo desde el interior: $617 \mathrm{~cm}$.

4. Fragmento de fuente o labrum.

Estancia IX / 4-bis.

Caliza pulimentada.

Diám. interior aprox: 10'2 cm.; Anch. máx. del pico vertedor: 4'21 cm.; long. máx. del mismo desde el interior: 4'59 $\mathrm{cm}$.

Muy similar al anterior, aunque tallado en diferente material y de menor tamaño.

Tanto la pieza $\mathrm{n}^{\mathrm{a}} 4$ como la 4-bis -si bien especialmente la primera- son muy similares a la taza de caliza que tal vez fue labrum del mitreo y luego reutilizada en la fuente de la Villa del Mitra, en Cabra (Córdoba). Este asentamiento presenta una planta muy semejante a la de la villa de El Ruedo, así como una evolución cultural y cronológica prácticamente idéntica. Pese a todo, aunque se trata, como en los casos que nos ocupan, de un recipiente tallado en una sola pieza, liso por dentro, en el exterior presenta una decoración de motivos geométricos y vegetales estilizados que se atribuye a la primera mitad del s. III d.C. (4). Constituye, pues, un paralelo en cuanto a la morfología y tal vez la funcionalidad de las piezas de Almedinilla, pero la cronología de éstas tal vez deba ser fijada un poco más tarde, a fines del s. III o comienzos del s. IV d.C.

5. Fragmento de mármol.

Estancia IX / Muro N / 5.

Mármol blanco, con abundantes concreciones.

Long.: 23'5 cm.: Gros. medio: 6/7 cm.

Fragmento prácticamente informe. Resulta difícil apreciar si se trata de un resto escultórico o arquitectónico. Presenta una de sus caras alisadas de manera tosca.

6. Ala derecha. Fragmentos (Lám. 11,6).

Estancia IX / Muro NO / 6.

Estancia XI / Sector O / 33.

Mármol blanco, de grano muy fino.

Long. máx.: 19*8 cm.; Anch. máx.: 7 cm.; Gros. máx. (mitad superior): 2'4 cm.; Gros. mín.: 2'4 cm.

(4) BLANCO, A; GARCÍA, J.; BENDALA, M.: 'Excavaciones en Cabra (Córdoba). La Casa del Mitra (Primera Campaña, 1972)", HabisIIÍ, 1972, pp. 279-319.

Como obra más reciente, aunque todavía en prensa (agradecemos a los autores las facilidades prestadas para su consulta), JIMÉNEZ SALVADOR, J.L.; MARTIN-BUENO, M.: La Casa del Mitra. Cabra, Córdoba, limo. Ayuntamiento de Cabra. 
Dos fragmentos hallados en diferentes estancias de la villa, que componen un ala derecha tallada por ambas caras, si bien el trabajo se ha esmerado sobre todo en la anterior, en la que las plumas aparecen algo más rebajadas.

\section{Ala izquierda. Fragmento.}

Estancias X-XI /13.

Mármol blanco, con algunas concreciones.

Long. máx.: 8'4 cm.; Anch. máx.: 3'2 cm.; Gros. máx.: 1'5 cm.

Plumas de forma redondeada y pequeño tamaño talladas en el anverso. Reverso con fuerte capa de concreciones que impide apreciar la labra. Pertenece a una figura distinta que la anterior.

\section{Ala izquierda. Fragmento.}

Estancia XI / Sector O / 22.

Mármol blanco.

Long. máx.: 18'5 cm.; Anch. más.: 6' 8 cm.; Gros. máx. (en borde superior): 2' $8 \mathrm{~cm}$.; Gros. mín.: 1'5 cm.

Aparece tallada en ambas caras, pero con las plumas rebajadas sobre todo en su superficie anterior. Es muy similar en tamaño y morfología a la $n^{25} 6-33$, pero no idéntica, ni en forma, grosor, ni detalles de labra, por lo que creemos que debió formar parte de otra figura. Las plumas aparecen como formas ovoides cortadas por una línea longitudinal que se superponen a la manera de escamas.

\section{Ala derecha. Fragmento.}

Estancia XI / Sector NO / 34.

Mármol blanco.

Long. máx.: 14 cm.; Anch. máx.: 6'7 cm.; Gros. medio: 1'5 cm.

Representa la parte inferior del ala, en la que tras la zona con plumas talladas a la manera de escamas, de pequeño tamaño, se extienden las plumas finales, labradas en sentido longitudinal, casi paralelas, aunque con tendencia a converger en la punta. El reverso apenas aparece desbastado. No parece pertenecer a ninguna de las otras alas documentadas.

10. Ala derecha. Fragmento (Lám. 11,41).

Estancia XI / Sector E / 41.

Mármol blanco.

Long. máx.: $15 \mathrm{~cm}$.; Anch. máx.: 8' $1 \mathrm{~cm}$.; Gros. máx. (en el reborde que enmarca el ala por el exterior): 2' $2 \mathrm{~cm}$; Gros. mín.: 1'6 cm.

Aparece tallada por ambas caras, si bien en el reverso la labra se limita a ligeras acanaladuras que sugieren el plumaje, mientras en el anverso el escultor se recrea en su trabajo. Presenta una cierta similitud con el fragmento $\mathrm{n}^{\mathrm{a}} 22$, de características formales bastante uniformes. Aún así, la pieza que nos ocupa parece de mayor tamaño y dibuja un vuelo diferente, lo que, a pesar de todo, puede deberse a una asimetría en la representación.

Nos hallamos, en definitiva, ante un mínimo de 3 figuras aladas que posiblemente deban interpretarse como Eróles o putti relacionados con el programa iconográfico que decoró las estancias centrales de la villa. Sin embargo, ninguna de las figuras conservadas muestra huellas de haber estado dotada de alas, por lo que hemos de suponer que los personajes a que 
pertenecieron se han perdido en todos los casos.

11. Grupo escultórico que representa la leyenda de Perseo y Andrómeda (Lám. 1,7). Estancia X / 7.

Estancia XVII / Desmonte N / 43.

Mármol blanco, con abundantes concreciones.

Alt. total conservada: 63'4 cm.; Alt. de Andrómeda: 51 '5 cm.; Fondo aprox. de la base: $27 \mathrm{~cm}$.

El cuerpo de Andrómeda se rompió a la altura de las rodillas y la pieza, así fracturada, fue recuperada en el interior del estanque biabsidado, junto a la figura de Attis, en su ábside N. Por el contrario, la parte inferior del grupo apareció en el ángulo NO de la Estancia XVII, al eliminar una de las terreras acumuladas junto al talud de la carretera que une Fuente Tójar y Almedinilla, después levantada parcialmente para continuar la excavación bajo ella. Por su enorme peso, creemos que esta última pieza debía hallarse en la estancia en que pudo estar expuesta, mientras que la figura de Andrómeda, una vez fragmentada, habría sido arrojada al estanque.

De la figura de Perseo sólo se conserva la parte inferior de las piernas y los pies.

Bulto redondo.

En líneas generales es obra correcta, tal vez algo sumaria en detalles concretos del modelado. Andrómeda aparece representada en el momento en que, tras ser liberada por Perseo, desciende de la roca, recogiéndose el vestido con la mano derecha. Viste chiton cogido sobre el hombro izquierdo con una fíbula circular de 2'5 cm. de diámetro muy deteriorada. Los pliegues adolecen de cierta rigidez. Su pie izquierdo casi se difumina en la roca de base. Aunque la figura ha perdido la cabeza -unida al tronco mediante una espiga de hierro- podemos saber que llevó el pelo suelto, como puede deducirse del bucle conservado sobre el hombro derecho.

A la izquierda de Andrómeda se ven los pies de Perseo. Bajo uno de ellos -el derecho-, se aprecia la cabeza de un monstruo con orejas puntiagudas y fauces abiertas que, a la manera de una gran serpiente con aletas, se retuerce hasta conseguir que aquélla pase a ocupar un primer plano, resaltando su derrota mediante el hecho de que Perseo la pisa, dominándola. El monstruo ha perdido su parte posterior. A las roturas antiguas han venido a sumarse ligeros desperfectos en la pierna izquierda provocados en el momento de la localización de la escultura.

El mayor interés de esta pieza radica en ser la única representación escultórica de este tema conocida en la Península Ibérica. Parece inspirada en una creación pictórica helenística que conocemos en varias versiones conservadas en Pompeya (5). Una de las más similares es la de la Casa de los Dioscuros, pintura mural prácticamente idéntica a la escultura que nos ocupa en cuanto a su composición, si bien con diferencias de detalle tales como la disposición del monstruo, el fondo de la escena, o la presencia -habitual, por otra parte- de alas

(5) DAREMBERG, Ch.; SAGLIO, Edm, Dictionnaire desaniquiles grecques et romaines, t.1, Graz, 1969, s.v. Andrómeda, pp. 268-269; t. IV. 1, s.v. Perseus, pp. 398-406.

EAA., Vol. I, Roma, 1958, s.v. Andrómeda, pp. 362-364; Vol. VI, Roma, 1965, s.v. Perseo, pp. 66 ss.; Perseo, Pittore di, pp. 69 ss.

SCHMALTZ, B.: "Andrómeda. Ein Campanisches Wandbild",/.dV 104,1989, pp. 259-281.

KAHIL, L. (dir), Lexicón Iconographicum Mithologiae Classicae, Vol. I, s.v. Andrómeda, pp. 623-643, especialmente Figs. 38,40 (para el monstruo) y 67 a 75. 
en los pies de Perseo. Se trata, por tanto, de ligeras variantes iconográficas que pueden deberse simplemente a las posibilidades tan diferentes que ofrecen medios distintos como son la pintura y la escultura.

La cronología de la mayor parte de estas representaciones se cifra en el tercer cuarto del s. I d.C, por lo que no debe extrañarnos que la pieza de Almedinilla pueda llevarse a finales de este siglo o tal vez incluso a comienzos del s. II d.C. (6).

12. Representación de Attis conforme al esquema iconográfico habitual (Lám. 111,8).

Estancia X/8.

Estancia XI / 16.

Estancia XI / Sector E /18.

Estancia XI / 20.

Mármol blanco amarillento, con vetas anaranjadas y violáceas. Altura total conservada: $59 \mathrm{~cm}$.

Se trata de una estatua tallada en bulto redondo, si bien su espalda (que coincide con el reverso de la capa) aparece totalmente plana, lo que tal vez indica su ubicación en una hornacina o al menos su adosamiento a muro o estructura similar. Sujeta la clámide sobre ambos hombros con dos fíbulas de tendencia circular, la derecha de $6^{\prime} 5 \mathrm{~cm}$. de diámetro máximo y la izquierda de $4 \mathrm{~cm}$. En el cuello conserva el orificio para el vastago de hierro que lo debió unir a la cabeza, perdida al igual que el brazo derecho, si bien hemos podido documentar la mano que sujetaba la barbilla $\left(n^{\circ} 18\right)$.

La escultura fue destrozada de antiguo y entre sus fragmentos hemos recuperado, además de la mano citada, todo el cuerpo $\left(\mathrm{n}^{\mathrm{e}} 8\right)$, la pantorrilla izquierda $\left(\mathrm{n}^{\mathrm{Q}} 20\right)$ y los pies, con una pequeña base que debió ir embutida en un pedestal $(n-16)$. Toda la figura presenta una fuerte capa de concreciones calcáreas -a excepción de la espalda- que hemos limpiado tan sólo en su costado interior derecho con objeto de apreciar la calidad del mármol.

Gran detallismo en la representación de paños, dedos, uñas, etc. Riqueza de pliegues, bastante simétricos en ocasiones. Tres de ellos, verticales, caen entre las piernas, centrando la composición. La clámide se prolonga por el lado derecho hasta tocar la pequeña base en que apoyan los pies, sirviendo de tercer punto de apoyo a la figura. Berceguíes con lazo y adornos reproducidos con detalles.

En atención al esquema iconográfico, la escultura de Attis que tratamos se incluiría en el Grupo B de García y Bellido (7), si bien dentro de él su paralelo más exacto sería el de Carmona: figura en actitud pensativa, pero con las piernas situadas en paralelo, no cruzadas (aún así se trata de una relieve, no de una estatua exenta, y se halla en un pésimo estado de conservación).

En general, las representaciones de Attis se vinculan al culto funerario -hecho probado indefectiblemente en la necrópolis de Carmona (8)-, como deidad protectora de los muertos y de la resurrección. No obstante, su presencia no implica necesariamente la existencia de culto como tal dado que fue motivo habitual en los repertorios iconográficos, aunque sí se

(6) Tanto las precisiones estilísticas a que nos referimos en nuestro trabajo como las que atañen a la cronología de las piezas, suponen tan sólo el resultado de una primera aproximación a las mismas. No hay que descartar, por tanto, que una vez estudiada en detalle toda la bibliografía, así como la morfología de las esculturas, nuestra hipótesis de trabajo pueda experimentar desviaciones en uno u otro sentido.

(7) GARCÍA Y BELLIDO, A.: Les religions orientales dans l'Espagne romaine, Leiden, 1967, pp. 59 ss.

(8) BENDALA GALÁN, M.: La necrópolis romana de Carmona (Sevilla), Sevilla 1976, vol. I, pp. 49 ss.

--- Grupo de investigación P.A.I. HUM 236 | http://www.arqueocordoba.com/publ/anales.htm ----131 
puede afirmar que, pese a constituir una religión de origen oriental, su frecuencia se hace máxima en las áreas más romanizadas (9).

Así, es preciso incidir en que los documentos relacionados con Attis se concentran en el área central de la Bética y zona mediterránea, si bien resultan especialmente abundantes en las provincias de Sevilla y Córdoba, donde, en concreto, testimonios de Attis se conocen en Fernán Núñez, Lucena, Zambra, Montilla y la propia capital (10). La única escultura de Attis fechada con fiabilidad es la de Carmona, cuya cronología ha sido llevada a época julioclaudia; de ahí que sea uno de los ejemplos más antiguos de la presencia de este culto en la Península.

Por el momento, no nos es posible asignar una cronología precisa en la pieza de Almedinilla, pero no creemos que deba ser fijada más allá de mediados del s. II d.C, en época de los Antoninos, con los que el culto a Attis acentúa su pujanza en Roma (11).

13. Altorrelieve con representación de bóvidos, en dos fragmentos (Lám. IV,9).

Estancia X / Ábside N / 9.

Mármol blanco con fuertes concreciones.

Alt.: 23 '5 cm.; Anch.: 38 cm.; Gros. con el cuerpo de los animales: 10'8 cm; Gros. de la placa óe base'. 6' $6 \mathrm{CY}$;l.

Representa a dos vacas o bueyes a la izquierda, enmarcados por una pilastra a la derecha. Esta presenta sección rectangular, con una base angular compuesta por tres toros y dos escocias. Remata el relieve por la derecha, dando origen a una cara de $8^{\prime} 3 \mathrm{~cm}$. de espesor trabajada de manera rugosa. Destaca el perfecto estudio anatómico de los animales, que debieron formar parte de una escena de carácter bucólico.

14. Altorrelieve en dos fragmentos.

Estancia XI / Sector E / 17.

Estancia LXVII / 66 y 67.

Mármol blanco con fuertes concreciones.

Alt.: 9'6 cm.; Anch.: $16 \mathrm{~cm}$.; Gros. de la placa de base: 2'2/2'7 cm.

Aparece enmarcado a la izquierda por una pilastra idéntica a la que delimita la pieza anterior por su derecha, lo que creemos confirma su pertenencia a una misma escena. En él aparecen la pantorrilla izquierda y los pies de un personaje a la derecha que se nos ha perdido, si bien puede pertenecer a él nuestra pieza $\mathrm{n}^{\mathrm{fi}}$ 66, recuperada en la Estancia LXVII, fragmento de altorrelieve que representa el abdomen y parte de las piernas de una figura con faldellín, que tanto estilística como formalmente y en lo que respecta a tamaño coincide con las piezas anteriores (Long. conservada: 10'1 cm.; Grosor de la base del relieve: 2'2 cm.; Grosor total: $5 \mathrm{~cm}$.).

El personaje que nos ocupa se apoya sobre una especie de peana trabajada en el mismo bloque, de manera que la pierna derecha escapa a lo que es el relieve en sí. Podría tratarse de un pastor o del personaje que completaba la escena con bueyes $\left(\mathrm{n}^{\mathrm{fi}} 9\right)$, componiendo un

(9) Un ejemplo muy similar, incluso del mismo tamaño, aunque con las piernas cruzadas en BALIL, A.: "Esculturas romanas de la Península Ibérica", B.SAA. LIV, Univ. de Valladolid, 1988, pp. 225, n9 184.

Para su dispersión en el resto del Imperio, ver por ejemplo EAA. vol. I, Roma, 1958, s.v. Attis, pp. 906 ss.; KAHIL, L. (dir.) Lexicón Iconographicum Mühologiae Classicae, vol. I, s.v. Attis, pp. 22 ss.

(10) GARCÍA Y BELLIDO, A., Op. cit., nota 7, pp. 56 ss.

(11) BENDALA GALÁN, M., Op. cit., nota 8, pág. 54. 
cuadro de carácter bucólico, muy en relación con el resto de esculturas documentadas. Parte posterior totalmente alisada.

15. Fragmento de relieve.

Estancia LXVII / 60.

Mármol blanco, con densa capa de concreciones.

Alt. total conservada: 10'40 cm.; Gros. total: 6'9 cm.; Gros. de pilastra: 2'9 x 3 x 4' $1 \mathrm{~cm}$.

En él se representa una pilastra de sección pentagonal utilizada como elemento de carácter arquitectónico o paisajístico en una escena similar a la que acabamos de describir. Esta pilastra apoya de nuevo sobre una basa moldurada a base de pequeños toros. Reverso plano. El relieve continuaba por ambos lados, si bien se ha perdido.

16. Fragmento de estatua en bulto redondo (Lám. 111,10).

Estancia X / Ábside N / 10. final.

Mármol blanco, con algunas concreciones, si bien se observa perfectamente el pulido

Altura conservada: $17^{\prime} 7 \mathrm{~cm}$.

Representa el abdomen y la parte superior de los muslos de un personaje infantil, aún sin vello púbico pero rayando en la adolescencia. Además de las roturas de tronco y piernas, presenta seccionados -ya de antiguo- los órganos genitales. Talla de gran calidad.

En función del fragmento conservado, resulta difícil una interpretación iconográfica de la pieza. Tal vez se trata de un personaje similar a nuestro $\mathrm{n}^{\text {a }}$ de inventario 53. Sin embargo, éste va cubierto de clámide y presenta el dorso plano, posiblemente para ser adosado a un nicho o pared, mientras que la escultura que tratamos aparece tallada en bulto redondo. Por este motivo, aunque con todas las reservas derivadas de un primer estudio, creemos que puede relacionarse más bien con el tipo del Dionysos del Museo Arqueológico de Valladolid o con algunas divinidad masculina juvenil (12), hipótesis que evidentemente debe ser mucho más contrastada, ya que la identificación es posible con otros muchos modelos iconográficos.

17. Herma decorativa, con peinado helenizante (Lám. IV, 11).

Estancia X / Ábside N / 11.

Marmol blanco, cubierto de una densa capa de concreciones calcáreas que hemos limpiado en la mitad izquierda de la cara. Alt.: 15'2 cm.; Anch.: 11'4 cm.; Gros.: 7'2 cm.

El pelo forma una trenza que se recoge hacia atrás a partir de la frente. A ambos lados rosetas de cinco pétalos y hojas de vid y yedra componiendo el tocado. Utiliza el trépano en la nariz, pelo y orejas. Ojos con párpados bien marcados. Dorso plano, perfectamente alisado. Cuello seccionado, aunque se ha intentado regularizar el corte. Boca entreabierta, en la que se ven los dientes.

Muy probablemente representa a Dionysos.

(12) GARCÍA Y BELLIDO, A., Op. cit., nota 7, n- 83 y 84, Lám. 72, pág. 98.

BALE., A.: Esculturas romanas de la Península Ibérica. I, Studia Archaeologica 51, Univ. de Valladolid, 1978, pp. $23 \mathrm{ss}, \mathrm{n}^{\mathrm{e}} 13$,Lám.XI. 
18. (Herma) con peinado femenino (Lám. IV,12).

Estancia X / Ábside N / 12.

Mármol anaranjado, cubierto por una gruesa capa de concreciones que ha sido eliminada igualmente en la mitad izquierda de la pieza.

Alt.: $15 ' 5$ cm.; Anch.: 10'7 cm.; Gros. máx.: 8'1 cm.

$\mathrm{Al}$ igual que la anterior, fue recuperada en el interior del estanque biabsidado. Cejas y párpados muy bien marcados, plegados estos últimos formando "patas de gallo". Nariz plana, tratada de manera idéntica a la figura anterior. Boca entreabierta, con ligeros desperfectos en labio inferior y barbilla. Pliegue horizontal en la base del cuello. Orejas talladas con gran delicadeza, perforadas en el lóbulo inferior para pendientes. Peinado distribuido a partir de una raya central, de la que parte en ligeras ondulaciones hasta formar una diadema de rizos sobre la frente y sienes -perfectamente simétrica- en los que se ha utilizado el trépano. Tras las orejas, el pelo cae en tirabuzones. La sección del cuello, pulida, indica que la figura fue concebida así, sin busto. Dorso plano, aunque con pequeñas entalladoras para facilitar su adosamiento.

\section{Cronología: época neroniana.}

Se trata de dos esculturas concebidas como hermae, que irían colocadas sobre pilarillos en los peristilos, jardines y otros espacios abiertos de las casas romanas. Suelen representar a Dyonysos, Hermes, Pan, ménades, Ariadna, Sileno, Príapo, faunos... y su cronología, bifrontes o no, se centra normalmente en época antoniniana, destacando como primordial su carácter decorativo y doméstico (13). No obstante, si bien en el caso que nos ocupa las hermae han sido recuperadas en un ambiente acuático y de jardín, sus características formales -especialmente en lo que a la pieza femenina se refiere- nos llevan a asignarles una cronología algo más alta, tal vez época de Nerón o poco más tardía -ello suponiendo que ambas esculturas sean contemporáneas-.

19. Pequeña cabeza de figura posiblemente femenina, con moño (Lám. V,14).

Estancia X / Ábside N / 14.

Mármol blanco, de grano muy fino, con concreciones, sobre todo en el pelo.

Alt. máx.: 14 cm.; Anch. máx.: 9'6 cm.; Gros. máx. con moño: 12'3 cm.

Fue seccionado del cuerpo a la altura del cuello. Rasgos bastante idealizados. Párpados tallados de manera sumaria. Nariz muy recta, con ligeros desperfectos que afectan también al lado inferior. Peinado de ondas que a partir de los parietales se recoge con una cinta hasta terminar en un moño de sección más o menos cuadrada. En la parte superior de la cabeza, sobre el frontal, un moño alto, en forma de lazo (Krobylos). El peinado se separa de la cara, sobre todo en su mitad derecha, mediante una línea muy marcada, casi una incisión. En los lóbulos de las orejas presenta un ligero abultamiento que podría hacer pensar en unos pequeños pendientes.

La pieza podría representar a una divinidad femenina o personaje relacionado con la iconografía de Diana o Venus, que copia el peinado característico de las versiones helenísticas de los tipos del siglo IV. Una pieza similar se conserva en el Museo

(13) Este tipo de piezas están siendo objeto últimamente de un estudio sistemático a cargo de P. Rodríguez Oliva. Un magnífico resumen bibliográfico aparece recogido en su artículo "Una herma decorativa del Museo Municipal de San Roque (Cádiz) y algunas consideraciones sobre este tipo de esculturillas romanas", Baetica 11, Univ. de Málaga, 1988, pp. 215-229. 
Arqueológico de Tarragona y es fechada en el s. II d.C. avanzado (14).

20. Fragmento de mármol blanco, remate de un paño o similar.

Estancia XI / Sector O / 21.

Long. máx.: 5'6 cm.; Anch.: 5'3 cm.; Gros.: 5'1 cm.

Presenta fractura en dos de sus lados, uno de los cuales parece conectar con un elemento de carácter arquitectónico, tal vez una columnita. Evidentemente perteneció a una pieza mayor.

21. Fragmento de mármol blanco en muy mal estado (se desintegra en arena con enorme facilidad).

Estancia XI / Sector N / 24.

Long. máx.: 7'2 cm.; Anch. máx.; 4'1 cm.; Gros. máx.: $3 \mathrm{~cm}$.

Ofrece restos de talla en una de sus caras. Parece tratarse de un fragmento de paño o manto, a juzgar por los pliegues representados. Imposible determinar su funcionalidad e interpretación.

22. Pequeño grupo fragmentado de antiguo que posiblemente representa el mito de Télefos (Lám. V,25).

Estancia XI / 25.

Estancia XI / Sector O / 36 y 42.

Estancia LXVII / 61 y 62.

Mármol blanco, cubierto por una densa capa de concreciones que se han limpiado parcialmente en la cara y pecho del personaje.

Altura total de la pieza: $31 \mathrm{~cm}$.

Este grupo, que se rompió ya de antiguo (nuestros números de inventario responden a la base del mismo; parte de la pierna y glúteo izquierdos del personaje; rodilla izquierda, torso y cabeza de éste, respectivamente) aparece incompleto. Representa a una figura juvenil pero muy musculosa, vestida tan sólo con una clámide y sentada sobre sus glúteos, con las piernas flexionadas y el cuerpo en una posición bastante violenta, doblado ligeramente hacia adentro a la altura del estómago, a la vez que la cabeza se vuelve en sentido contrario, hacia atrás. Dobla completamente la pierna derecha sobre la que descansa, pero la pierna izquierda la llevaba extendida formando más o menos un ángulo recto, a juzgar por la rodilla conservada.

Talla bastante sumaria, en lo que a cabeza y tronco se refiere. La clámide presenta un reborde o doblez que rodea el cuello del personaje por delante y por detrás, donde forma una especie de trenza, y una prolongación de su extremo inferior que se continúa por la cadera derecha tapando posiblemente -la pieza se halla en muy mal estado en esta parte- sus genitales. Delante de las rodillas aparecen las pezuñas de un animal ungulado, tal vez un bóvido o un cérvido.

El brazo derecho, parcialmente perdido, muestra orificio para grapa de unión. En la cabeza el pelo, muy poco trabajado, forma una especie de casquete que cae sobre las orejas. Tanto en éstas como en el flequillo se ha utilizado el trépano. Todo el grupo va montado sobre una base que aparece muy fragmentada, pero plana en su cara inferior. 
De nuevo nos hallamos, a nuestro juicio, ante un prototipo de carácter helenístico que, a manera de hipótesis, puede relacionarse con el mito de Télefo, hecho célebre por un cuadro de Apeles, cuya mejor copia conservada procede de la basílica de Herculano y se guarda en el Museo de Nápoles (15). Esta pintura representa el momento en que Hércules reconoce a Télefo como hijo propio en presencia de Arcadia y otros personajes. Télefo aparece retratado en el ángulo inferior izquierdo como un niño que mama de una cierva, de acuerdo con la leyenda. Formalmente adopta una postura casi idéntica a la pieza de Almedinilla y aunque ésta presenta diferencias tales como el que alarga los dos brazos hacia adelante, posiblemente para sujetar la ubre de la cierva, en posición distinta a la pintura reseñada, la presencia junto a sus rodillas de una pezuña parece ofrecer la clave para su interpretación.

Su cronología, a juzgar por aspectos tales como la utilización del trépano, la disposición de una clámide sobre el cuerpo o las características de la talla creemos que no debe ser anterior al s. II d.C.

23. Fragmento de mármol blanco, con restos de talla.

Estancia XI / Sector E / 31.

Long. máx.: 4'4 cm.; Gros. máx.: 2'3 cm.; Gros. mín.: 1'5 cm.

Interpretación indeterminada. Podría tratarse de un pie, parte de una pierna o cualquier otro elemento similar. Tiene aspecto relativamente cilídrico, con un abultamiento en uno de sus extremos y una ligera acanaladura en una de sus caras. Podría representar también la pata de un animal, tal vez atribuible al grupo anterior.

24. Fragmento de mármol blanco, tallado.

Estancia XI / Sector O / 32.

Long. máx.: 6'7 cm.; Anch. máx.: 8'1 cm.; Gros. máx. 4'5 cm.

Pertenece al parecer al remate de un paño, con los pliegues acanalados típicos de este género de representaciones.

25. Fragmento de mármol blanco, tallado.

Estancia XI / 35.

Long. máx.: 8'5 cm.; Anch. máx.: 5'9 cm.; Gros. máx.: $4 \mathrm{~cm}$.

Fracturas antiguas de su mitad anterior y del lado derecho. Parece representar el hombro, con parte del brazo izquierdo y de la espalda de una estatua en bulto redondo. Por el tipo de mármol -como ya hemos señalado repetidamente, pendiente de análisis petrográficospodría pertenecer ajiuestra figura $\mathrm{n}^{\mathrm{fi}} 10$.

26. Fragmento de mármol blanco, tallado en forma de rectángulo.

Estancia XI / Sector O / 37.

Fuertes concreciones.

Long. máx.: 5'7 cm.; Anch. máx.: 2'7 cm.; Gros. máx.: 2'5 cm.

Se trata posiblemente de un elemento arquitectónico o algo similar, aunque de difícil

(15) MORENO, P.: Pintura griega, Ed. Mondadori España S.A., Madrid, 1988, pp. 156-157, Fig. 176. E.A.A., vol. VII, Roma, 1966, s.v. Télefo, y Telephos, Pittore di, pp. 669 ss. Queremos aprovechar la ocasión para mostrar nuestro agradecimiento a M. Bendala Galán, a cuya indicación personal debemos el reconocimiento del tipo. 
interpretación. Sección más o menos cuadrada. De una de sus caras parte algo que se ha perdido.

27. Fragmento de mármol blanco, tallado.

Estancia XI / Sector O / 39.

Long. máx.: 6'8 cm.; Gros. máx.: 2'1 cm.

Forma pseudocilíndrica. Función e interpretación indeterminadas.

28. Dos fragmentos de mármol blanco.

Estancia XI / Sector E / 40.

Tamaño minúsculo. Imposible interpretación.

29. Brazo y mano izquierdos sosteniendo una palma - Fragmento (Lám. VI,52).

Estancia XVII / 52.

Mármol blanco.

Alt. máx.: $17 \mathrm{~cm}$; Gros. de la palma: 2'9 cm.; Anch. de ésta: $9 \mathrm{~cm}$.

Bulto redondo. La pieza se conserva en dos fragmentos que se fracturaron a la altura de la muñeca, si bien casan perfectamente. Talla de gran delicadeza, que se hace especialmente hábil en la mano, la cual -pese a que ha perdido los dedos índice y corazón- muestra en los conservados las uñas labradas con toda precisión. La mano fue recuperada en un plano bastante inferior al resto del brazo -roto a la altura del codo- y su conservación es mucho mejor, de manera que casi no presenta concreciones.

30. Fragmento de palma tallada en mármol blanco.

Estancia LXVII / 64.

Long. total: 9'9 cm.; Gros. máx.: 1'5 cm.; Anch. máx.: 9'5 cm.

Se trata de una pieza idéntica en factura, tipo de piedra y tamaño a la que empuña la mano anterior. Como ella, sólo aparece tallada por el anverso y presenta densas concreciones en el reverso. No obstante, los cortes no casan. Es un motivo o atributo que pudo portar algún personaje de los que suelen representar a las Estaciones, similar al que vamos a estudiar a continuación. Aún así, la talla es mucho más delicada e incluso el tipo de mármol distinto a simple vista, lo que tal vez puede resultar indicativo de una cronología diferente.

31. Joven desnudo con clámide, posible representación de una Estación (Lám. VII, 53). Estancia XX, 53.

Mármol blanco, con algunas concreciones.

Altura conservada: $52 \mathrm{~cm}$.

Personaje casi infantil con clámide, que sujeta en su hombro derecho mediante fíbula circular compuesta de tres aros de diámetro decreciente (diámetro máx.: 2'4 cm.). Formas blandas, llenas y carnosas, como se ve sobre todo en rostro y cuello. La cabeza aparece seccionada a la altura del occipital y presenta un orificio de $8 \mathrm{~mm}$. para grapa de sujeción a un aplique indeterminado.

Aparece ataviado a la manera oriental, con gorro ceñido por un lazo sobre la frente y puntas del pelo asomando a lo largo de toda ella. Este pelo se transforma en rizos que caen hasta los hombros desde las mejillas hasta la nuca. En él se ha utilizado sin pudor el trépano, al igual que en los orificios de la nariz y sobre el labio superior. Ojos ligeramente rasgados, 
sin iris, con párpados bien marcados. Boca pronunciada, con las comisuras muy destacadas por lo abultado de los mofletes. Barbilla con ligero hoyo central.

Se trata de una escultura tallada en bulto redondo, a excepción de la espalda, que aparece plana, como si hubiera estado expuesta en nicho u hornacina. Esto no evita que se haya tallado el pelo (si bien el trépano sólo se utiliza a ambos lados de la cara, en un claro intento de ganar en claroscuro), que cae en tirabuzones sobre la nuca y el reborde de la clámide. Esta apoya sobre el lado izquierdo del pecho hasta ser recogida por la mano izquierda, de la que cuelga un pliegue con fuerte sensación de claroscuro que apoya a su vez sobre la cadera. En el hueco formado por el brazo al recoger la clámide porta un nido en el que tres pichones con las alas desplegadas acuden a picotear algo que acaban de aportarles. En ellos la talla es más sumaria y, de hecho, los ojos, almendrados, aparecen conformados por una simple incisión. Diámetro del nido: $10^{\prime} 2 \mathrm{~cm}$.

Ombligo marcado con un simple círculo exciso. Pubis con dos pliegues ligeros que denotan la flaccidez, y cierta obesidad. Pliegue inguinal apenas marcado. Ausencia de vello púbico. Pene fracturado.

Brazo derecho desaparecido hasta la altura del codo. Piernas seccionadas bajo las rodillas. Mano izquierda un tanto desproporcionada, con las uñas muy bien definidas, tratadas de manera muy sumaria.

Talla muy realista, aunque parece bastante convencional.

A nuestro juicio, nos hallamos ante un geniecillo que podría simbolizar a una Estación, similar a los representados en el Sarcófabo de las Estaciones conservado en el Museo Municipal de Oporto, cuya cronología se sitúa a mediados del s. III d.C, tal vez "durante el principado de Gallienus" (16), y, sobre todo, a los que aparecen en el Sarcófago de las Estaciones de Ampurias, que se atribuye a finales del s. III o más bien a comienzos del s. IV d.C, a la vez que se considera una obra de importación (17).

Tanto en uno como en otro caso aparece en torno al difunto la representación de las cuatro estaciones, e incluso en este último García y Bellido cree ver un Attis que, a nuestro juicio, no es sino la representación del Invierno. En el sarcófago del Alemtejo los atributos de estos genios estacionales -que van dotados de alas, a la vez que ofrecen unas características estilísticas más lejanas a la pieza de El Ruedo que las del sarcófago de Ampurias, mucho más afín- son dos ánades en el caso del Invierno; una cesta con espigas de trigo el Verano; una cesta con flores la Primavera y un racimo de uvas el Otoño.

En el ejemplar de Ampurias el Invierno porta de nuevo dos ánades, a la vez que complementa la clámide con bracae que le cubren casi hasta la cintura; a continuación sigue un pastor con túnica corta portando un cordero sobre sus hombros y en el resto de los casos los atributos se han perdido, si bien entre las figuras aparecen perros, pájaros o árboles que indudablemente se relacionan con la Naturaleza. En ambos casos, cada personaje suele portar en su mano derecha una rama, que, en su mayor parte, resulta inidentificable. Si nuestra escultura la llevó es algo que desconocemos, al haber perdido el antebrazo derecho, pero con este tipo iconográfico debe poder relacionarse el brazo con palma descrito más arriba. 
De acuerdo, pues, con los atributos documentados en estos sarcófagos no sabemos a qué estación puede simbolizar la figura de El Ruedo, si bien como hipótesis puede señalarse la Primavera, época en la que tiene lugar por excelencia la reproducción de las aves.

Constituye la escultura más tardía con la que contamos en la villa y, sin duda, debe estar en relación con la gran reestructuración arquitectónica y de carácter decorativo que aquélla experimentó a fines del s. III o comienzos del s. IV d.C. En este momento el dueño de la villa reutilizaría por su valor artístico las esculturas que conservaba de etapas anteriores, pero al mismo tiempo mandaría completar los programas iconográficos; y a este gesto debe responder esta representación y posiblemente otras cuya cronología resulta por el momento más problemática.

\section{Fragmento de escultura en mármol blanco.}

Estancia XI / Sector N / 19.

Mármol blanco, con concreciones.

Long. máx.: 10'4 cm.; Anch. máx.: 7'2 cm.; Gros. máx.: 4'5 cm.

Conserva parte del pelo, compuesto por rizos en los que se ha utilizado el trépano, de la mejilla derecha y del arranque del cuello. Estilísticamente responde al mismo tipo iconográfico que la figura anterior, por lo que cabe interpretarlo igualmente como un posible genio estacional. La pieza presenta fracturas antiguas; no obstante, hay que destacar que el corte del occipital aparece picado con pequeñas entalladuras que podrían haber servido para facilitar la adhesión de la pieza a alguna superficie indeterminada. Imposible precisar si se trata de un relieve o de una pieza en bulto redondo.

32. Pequeña cabeza femenina (Lám. VI, 57).

Estancia LIX / 57.

Mármol blanco, cubierto por una densa capa de concreciones. Alt.: $12 \mathrm{~cm}$;; Anch. máx.: 9'5 cm.; Gros. máx.: 7'1 cm.

Fracturas a la altura del parietal y ojo izquierdos, así como en toda su mitad posterior, que se ha perdido. Estilísticamente ofrece una gran similitud con la herma $n^{\circ} 14$ de nuestro inventario, aspecto que se puede observar en la sumaria talla de ojos y boca, así como en la disposición del cabello a base de ondas y su delimitación con respecto al rostro de una manera muy marcada, casi como una incisión. Sin embargo, el mal estado de conservación general de la pieza -que afecta también a nariz y barbilla- impide concretar si constituyó una figura en bulto redondo o bien fue utilizada a la manera de herma (hipótesis menos probable, a nuestro juicio).

\section{Fragmento de busto.}

Estancia LXI / 59.

Mármol blanco, con algunas concreciones que afectan sobre todo al reverso, apenas pulimentado.

Alt.: 31 '5 cm.; Anch. máx. conservada: 17 cm.; Gros. máx.: 8'1 cm.; Gros. de la base del relieve: 4'5 cm.; Diám. de la fíbula: 4' $2 \mathrm{~cm}$.

Personaje con paludamentwn sujeto con fíbula de forma circular a la altura de la clavícula izquierda. Reverso convexo. Hueco para encajar la cabeza perfectamente delimitado. El plegado del paño aparece tallado a mediorrelieve, formando acanaladuras que se disponen de manera casi radial. La fractura de la pieza se ha producido precisamente 
siguiendo una de estas acanaladuras, en concreto la central, lo que ha dado lugar a un corte casi recto.

De acuerdo con todos los indicios, se trata de un busto para retrato que, en función de sus dimensiones relativamente reducidas, tal vez pueda ser llevado a época antoniniana (18).

34. Fragmento de mármol blanco, tallado.

Estancia LXVII / 63.

Alt. conservada: $16 \mathrm{~cm}$; Alt. del objeto fusiforme: 14'5 cm.; Diám. máx. del mismo: 4'5 cm.; Diám. de su base: 5'5 cm.

Representa un objeto de forma ovoide con base cóncavo-convexa, a la que da paso un fuerte estrangulamiento. Aspecto fusiforme, que recuerda al barrote de una balaustrada. Apoya sobre una base de mármol que se prolonga envolviéndolo por detrás en toda su extensión. Esta especie de envoltura aparece tallada por el reverso con pliegues verticales y oblicuos que recuerdan el plegado típico de los paños. Su funcionalidad, así como su interpretación nos resultan indeterminadas por el momento.

\section{Fragmento de pierna.}

Estancia LXVII / 65.

Mármol blanco.

Long. total: 9'5 cm.; Gros. máx.: 3'5 cm.

Se conserva desde la rodilla hasta el tobillo. En el lado izquierdo se observa un pequeño resalte que debió servir para fijarla a otro elemento que desconocemos, proporcionándole así una mayor estabilidad.

36. Pequeño brazo de bronce, macizo e incompleto (Lám. VIII, 72).

Estancia LXVII / 72.

Long. conservada: $16,5 \mathrm{~cm}$.

Presenta todos los dedos mutilados. Por otra parte, la fractura de unión con el hombro muestra por el exterior un pequeño rectángulo inciso, posiblemente perteneciente a un parche que debió servir para unirlo al cuerpo, lo que sugiere la fundición de la estatua en piezas diferenciadas.

(18) En este sentido, procedente al parecer de la villa de El Ruedo, se conserva en el M.A.N. ( $N$ - de inv. 2.770; Colección Miro) una cabeza del emperador Domiciano, que muy recientemente ha sido objeto de un estudio detallado a cargo de A.M* Vicent, quien prepara su publicación en el Boletín del MA.N. En principio, fue dada a conocer por A. Blanco Freijeiro ("Un retrato de Domiciano", AJEArq. XXVIII, 1955, pp. 280 a 286).

De acuerdo con sus dimensiones: Altura: $16 \mathrm{~cm}$.; Anch.: $12 \mathrm{~cm}$.; Diámetro del cuello (nuca-barbilla): $84 \mathrm{~cm}$., no puede relacionarse con el busto conservado, de proporciones mucho más próximas al natural. Su cronología se fija en el año 84 d.C. (Lám. VIII, 2770).

Por otra parte, existe una pieza citada por Maraver en el catálogo de los materiales recuperados en la necrópolis ibérica de los Collados (MARAVER Y ALFARO, L.: "Expedición Arqueológica a Almedinilla", Rev. de Bellas Arles e Histórico-Arqueologica, Serie II, t. II, Madrid, 1967, pp. 307-323) que probablemente procede también de El Ruedo y debe relacionarse con el mismo conjunto escultórico que presentamos. Se trata de un fragmento de mármol blanco que representa la mano derecha de una escultura femenina, sosteniendo entre sus dedos parte del manto. Su ingreso en el Museo tuvo lugar en 1867, como parte de la Colección entregada por la Comisión Provincial de Monumentos (VAQUERIZO GIL, D.: Aproximación al fenómeno de la Cultura Ibérica en la provincia de Córdoba. El yacimiento del Cerro de la Cruz (Almedinilla), Tesis Doctoral, Ed. microfilmada, Serv. de Publ. Universidad de Córdoba, 1989, pp. 130 y 304, nota 20 (Lám. VII, 27). 
Presenta una corrosión ligera estable, que afecta a la mayor parte de la superficie, con pátinas nobles no deformantes. Esta corrosión se debe básicamente a óxidos cúpricos y carbonatos.

37. Representación en bronce de Hypnos (Lám. IX y X).

Estancia XVII / 44, 46, 47, 48 y 49.

Estancia XXXVII / 54.

Cabeza: Alt.: 11'8 cm.; Anch. de la cara: 12'8 cm.; Long. del ala izquierda: $17 \mathrm{~cm}$; Long. del ala derecha: 15 '5 $\mathrm{cm}$.

Estatua en bronce de Hypnos o Somnus, de tamaño algo menor que el natural. Fue recuperada por partes, que se hallaron en las Estancias XVII (brazo derecho -44-; brazo izquierdo -50-; torso y pierna derecho -46-; pie derecho -47-; -pierna izquierda - 48- y mano derecha -49-) y XXXVII (cabeza alada -54-).

La figura aparece desnuda, inclinada hacia adelante en una violenta torsión del cuerpo; debió ir colocada en el nicho 1, abierto en el muro oeste del triclinium (o estancia XVII), donde hemos podido recuperar las tortas de plomo que fijaron los pies a la base, y fue objeto de una sistemática destrucción tras el abandono -o coincidiendo con él- de la villa, posiblemente a mediados o fines del s. V d.C.

Toda la pieza fue fabricada a la cera perdida en hueco, a excepción de la mano derecha, maciza, y en ella se puede distinguir claramente entre la cabeza y el cuerpo que, en cualquier caso, fueron fundidos por separado. La cabeza, recuperada en una estancia diferente a aquélla en la que apareció el resto del cuerpo, presenta un estado de conservación mucho mejor que el resto de la escultura y resulta ligeramente desproporcionada, por su menor tamaño, respecto al conjunto de la figura.

Está fundida en hueco con decoración modelada previa a su manufactura; lleva el pelo recogido mediante una cinta o taenia decorada con motivos vegetales de plata damasquinada y su peinado se distribuye, a partir de una raya central, en dos mitades sobre los parietales, tirabuzones a ambos lados de la cabeza, tras las orejas, y el resto del pelo en un moño a la altura de la nuca.

En las sienes le nacen dos alas, desplegadas y más o menos simétricas, si bien en la derecha aparecen seccionadas las plumas finales, al parecer como marca de taller, dado que este mismo detalle se observa en la cabeza del Hypnos conservada en el British Museum, que luego comentaremos.

Los ojos, que debieron ser de pasta vitrea, se han perdido. El rostro, de gran serenidad, muestra una expresión abstraída o soñadora.

La cabeza, seccionada del cuerpo por haber sido concebidas como dos piezas distintas, se acopla a él mediante un corte biselado, de sección aproximadamente circular, que presenta ligeros rebajes o acanaladuras perpendiculares a la línea del cuello, dispuestos en toda la sección con objeto de evitar el posible patinamiento de ambas partes.

En lo que respecta al cuerpo, hoy en día aparece fragmentado en varias piezas, de entre las cuales la mayor es la que aglutina el torso y la pierna derecha. Todo él fue fundido a la cera perdida en hueco, a excepción de la mano derecha -la única conservada-, fundida en macizo y soldada con el brazo mediante plomo. Este material aparece también en la palma de la misma, delimitando una especie de acanaladura que serviría para fijar el cuerno, perdido. Especial atención merece la posición de los dedos, de una extrema elegancia, con el meñique levantado en un gesto de gran delicadeza. Ha perdido el dedo pulgar. 
Por su parte, la pierna izquierda se ha fracturado poco más abajo del pliegue inguinal, por un punto donde aún son apreciables varios parches en forma de placas rectangulares, que debieron reparar alguna rotura antigua, o tal vez servir para acoplar la pieza, posiblemente fundida de manera independiente (Lám. X). Otro tanto se puede decir de la unión entre la pierna y el pie derechos, soldadas también mediante parches perfectamente visibles. En total hemos podido documentar unos 40 apliques de este tipo en el conjunto de la escultura, a excepción de la cabeza. En los casos descritos más arriba tienen como misión unir o soldar distintas porciones del cuerpo, fragmentadas o fundidas por separado. El resto fueron aplicados para tapar poros de gas producidos durante su fundición.

Los brazos, tanto el izquierdo como el derecho fueron fundidos en hueco y conservan más o menos desde el hombro a la muñeca. En ellos también es posible observar la existencia de parches y reparaciones, al menos 10 en el primer caso y 4 en el segundo. No hemos conseguido recuperar la mano izquierda.

Finalmente, en la cara interna de cada muslo se observan dos incisiones más o menos paralelas y de una longitud media de dos $\mathrm{cm}$. cuya funcionalidad o interpretación se nos escapan.

Tanto en el caso de la cabeza como en el del cuerpo, el grado de corrosión es ligero y mediano según las zonas, con pátinas nobles no deformantes. Conserva en general gran cantidad de núcleo metálico.

El único tratamiento realizado desde su extracción hasta hoy se ha basado en una limpieza mecánico-manual para eliminar los productos de alteración más superficiales. Una vez efectuada esta operación se ha observado que la capa de corrosión está constituida por un carbonado básico del bronce, que se forma por una reacción del óxido cúprico más agua y anhídrido carbónico. Se observan también gran cantidad de óxidos cuprosos y cúpricos, cloruros cuprosos y cúpricos y otros productos de corrosión propios del bronce (19).

La escultura, en su posición original -muy inestable por la fragmentación de la misma, lo que puede motivar alguna variación de detalle en esta primera medición- presenta una altura de $87 \mathrm{~cm}$. La lámina que la conforma cuenta con un grosor medio de 0'5 cm.

Nos hallamos ante una representación en bronce de Hypnos, personificación del Sueño en la mitología grecorromana que, según la opinión más extendida, copia un arquetipo -también broncíneo- del s. IV a.C, atribuido a Praxiteles, Skopas o Leochares, al parecer expuesto en un santuario de Asklepios como símbolo de las propiedades curativas del sueño. No obstante, según Blanco Freijeiro sería más correcto atribuirlo a los hijos de Praxiteles, en los primeros decenios del s. III a.C, que, a su juicio, es cuando la estatua debería fecharse por su composición y movimiento (20).

Hypnos, hijo de Nobe y hermano gemelo de Tánathos es representado en el momento en que, con actitud serena, avanza vertiendo el sueño sobre el mundo del cuerno que porta en su mano derecha. En la izquierda llevaría como atributo la flor de la adormidera, pero en el caso que nos ocupa la mano de este lado es precisamente la única pieza perdida.

(19) Queremos agradecer estos datos a D. José M. TALLADA LUCENA, Restaurador que contribuyó en su momento a la extracción de la pieza y que actualmente ejerce como Monitor de Restauración en los cursos patrocinados por el INEM que desde 1988 se vienen desarrollando en el Taller de Arqueología de Almedinilla.

(20) BLANCO, A.: Museo del Prado. Catálogo de la Escultura t: Escultura clásicas, Madrid 1957, n $\mathrm{n}^{\mathrm{s}}$ 89-E Hypnos pp. 68 ss., Láms. XLIII a XLV. 
Esta escultura de Almedinilla ofrece sus mejores paralelos en el Hypnos marmóreo del Museo del Prado, cuya cronología se sitúa en el segundo cuarto del s. II d.C, en época de Adriano (21); el Hypnos de Jumilla, que, aunque procedente de esta localidad murciana, se conserva en el Anticuarium de Berlín Oriental (22) y, sobre todo, la cabeza procedente de Civitella d'Arno, cerca de Perugia, conservada en el British Museum (23).

La pieza del Prado, con 1 ' $50 \mathrm{~m}$. de altura, representa un prototipo ligeramente diferente al de la villa de El Ruedo. Sin embargo, tanto el Hypnos de Jumilla, con 71 ' 5 cm. de altura, como la cabeza del B.M., con unos 20'5 cm. de envergadura, responden exactamente al mismo tipo y tamaño. El de Jumilla ostenta formas más maduras que el de Almedinilla. Por lo demás, coincide plenamente desde el punto de vista formal con el Hypnos de El Ruedo y otro tanto ocurre con la cabeza del British, ligeramente diferente en detalle -representa por ejemplo, de manera explícita, las orejas, que en nuestro caso quedan camufladas entre los tirabuzones; la boca, entreabierta, ofrece labios más carnosos, de modelado más pronunciado; la taenia no lleva decoración, etc.-, pero idéntica en aspectos tan importantes como el corte en el ala derecha y el que fuera fundida de manera diferenciada con respecto al cuerpo, ajusfando a éste mediante un corte en bisel del mismo tipo que el documentado en el Hypnos de Almedinilla. El diámetro de este corte es de 10'5 cm.

A pesar de que ambas obras presentan algunas diferencias, tanto en lo que respecta a la interpretación del tipo -más o menos infantil- como en lo que a técnica se refiere -la cabeza del British fue fundida en piezas diferenciadas- la pertenencia a un mismo taller es una hipótesis que no debe ser descartada, al menos sin intentar estudios estilísticos más profundos, así como, si ello es posible, análisis químicos del metal que los componen y de los procesos de fundición utilizados.

En lo que respecta a la cronología, en ninguno de los dos casos citados como paralelos inmediatos se especifica una fecha aproximada -García y Bellido tan sólo indicó que la pieza de Jumilla podía ser obra helenística, pero también de época romana-. Nosotros, sin un estudio más detallado tampoco podemos entrar en mayores precisiones, pero a manera de hipótesis inicial, creemos que su cronología no debe diferir mucho de la que Blanco asignó al Hypnos del Museo del Prado (24).

(21) TORMO, E.: Museo del Prado. Catálogo de las Esculturas I. Sala de las Musas, Madrid, 1949, n9 89, pp. 59 ss., Lám. 7. BLANCO, A., Op. cit. nota 20, pág. 69.

(22) GARCÍA Y BELLIDO, A., Hispania Graeca, Barcelona, 1948, Vol. II, n9 36, pp. 124 ss., Lám. LIV.

MOLINA GRANDE, M!.C; MOLINA GARCÍA, J.: Carla Arqueológica de Jumilla, Jumilla, 1973, pp. 119 ss.; Lám. XXI. Agradecemos desde aquíal Sr. Molina García, Director del Museo Municipal de Jumilla su amabilidad al enviamos información y fotografías acerca del Hypnos recuperado en esta localidad.

(23) WALTERS, H.B., Catalogue ofthe Bromes, Greek, Román andEtruscan, in the Department ofGreekand Román Antiquites, British Museum, London, 1899, n⿳2 267, pp. 34 (Gracias a J.R. Carrillo Díaz-Pinés por habernos proporcionado toda la documentación existente en el B.M. acerca de esta pieza, así como un reportaje fotográfico sobre la misma).

COOK, B.F., Greek and Román Art in the British Museum, B.M. Publications, London, 1976, pág. 179.

(24) Acerca de la evolución iconográfica del tipo, así como de su dispersión, ver por ejemplo: E.A.A., Roma, 1961, Vol. IV, s.v. Hypnos, pp. 62 ss.; DAREMBERG, Ch.; SAGLIO.Edm.: Dictionnaire des Antiquités Grecques el Romaines, Graz, 1969, vol. IV, 2, s.v. Somnus, pp. 1396 ss.; BOUCHER, S.: Recherches sur les bromes figures de Gaule pré-romaine el romaine, B.E.F. d'Athénes et de Rome, Rome, 1976, s.v. Somnus, pp. 154-155. 


\section{Recapitulación final}

Tras este breve catálogo a través del cual, precisamente por el carácter que hemos querido imprimir a esta publicación, no nos ha quedado más remedio que pasar casi a vuelo de pájaro, podemos concluir que nos hallamos ante un conjunto escultórico muy notable que, a su propio valor intrínseco, añade el haber sido recuperado en una excavación sistemática, o sea dentro de un contexto arqueológico claramente definido.

Constituye, por otra parte, un programa iconográfico bastante complejo, relacionado sin duda con la decoración de un ambiente de carácter lúdico y familiar -jardines, estanques, fuentes, triclinium-, que fue destrozado de manera intencionada tras el abandono de la villa -o coincidiendo con él- y la mayor parte de las piezas -especialmente las cabezas- arrojadas al agua, práctica que resulta habitual en la Antigüedad tardía.

Se trata de esculturas de varias épocas que, básicamente, responden a los tres momentos de esplendor de la villa: siglo I, s. II y principios del s. IV d.C. Las cronologías que les asignamos no dejan de ser meramente indicativas, en tanto se lleva a cabo un estudio de mayor profundidad. No obstante, resulta innegable que las esculturas del s. I permanecían aún expuestas en el siglo IV, lo que nos da idea de que su valor artístico -si no ya el meramente ideológico- fue captado en sus justos términos por el responsable de la última y gran reestructuración arquitectónica de la villa.

En cualquier caso, no cabe duda que las piezas correspondientes al encargo más antiguo, caso del grupo de Perseo y Andrómeda o el que representa el mito de Télefo, posiblemente inspiradas en cartones pictóricos, denotan buen conocimiento del arte de élite de la época, lo que es lo mismo que decir de la cultura tardohelenística. Si las esculturas fueron importadas o encargadas en un taller local o provincial es algo que no podemos precisar por el momento, pero no cabe duda de que esta constituye una más de las líneas por la que debe orientarse el estudio en profundidad de las piezas, trabajo que podrá aclarar aspectos de tanta importancia como la procedencia del mármol, las características de la talla y de la fundición, la colocación de las figuras y todas aquellas derivaciones ideológicas relacionadas con el análisis detallado de los programas iconográficos (25).

(25) Ver en este sentido obras recientes como la de R. NEUDECKER, Die Skulpturen - Aussíattung Rómischer Villen in Italien, philip. von Zabern, Mainz am Rheim, 1988, donde se aborda un estudio de los programas escultóricos documentados en villas romanas de Italia muy similar al que deberá ser acometido con respecto al conjunto de Almedinilla. 


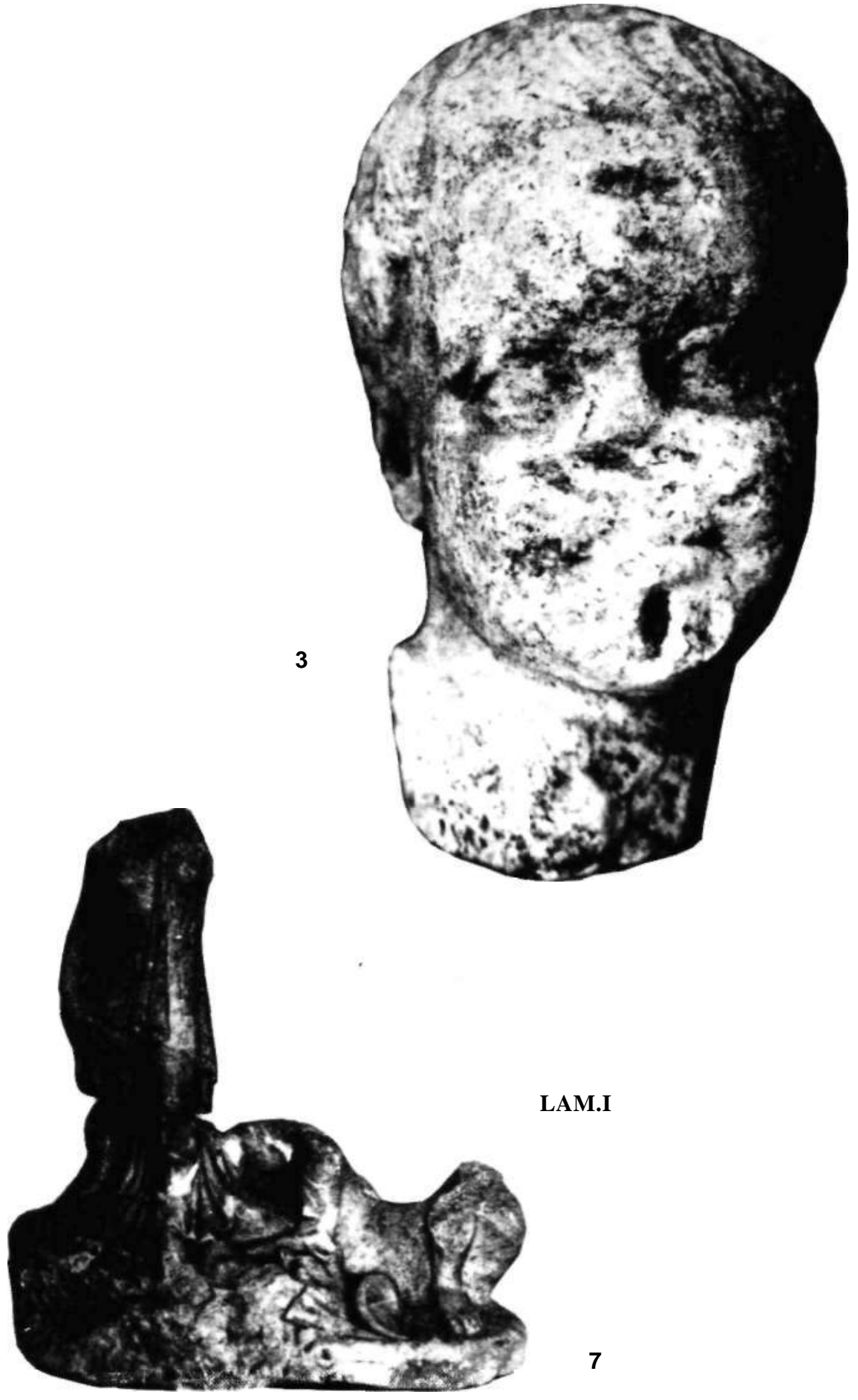

--- Grupo de investigación P.A.I. HUM 236 | http://www.arqueocordoba.com/publ/anales.htm --- 



LAM. II

--- Grupo de investigación P.A.I. HUM 236 | http://www.arqueocordoba.com/publ/anales.htm --- 

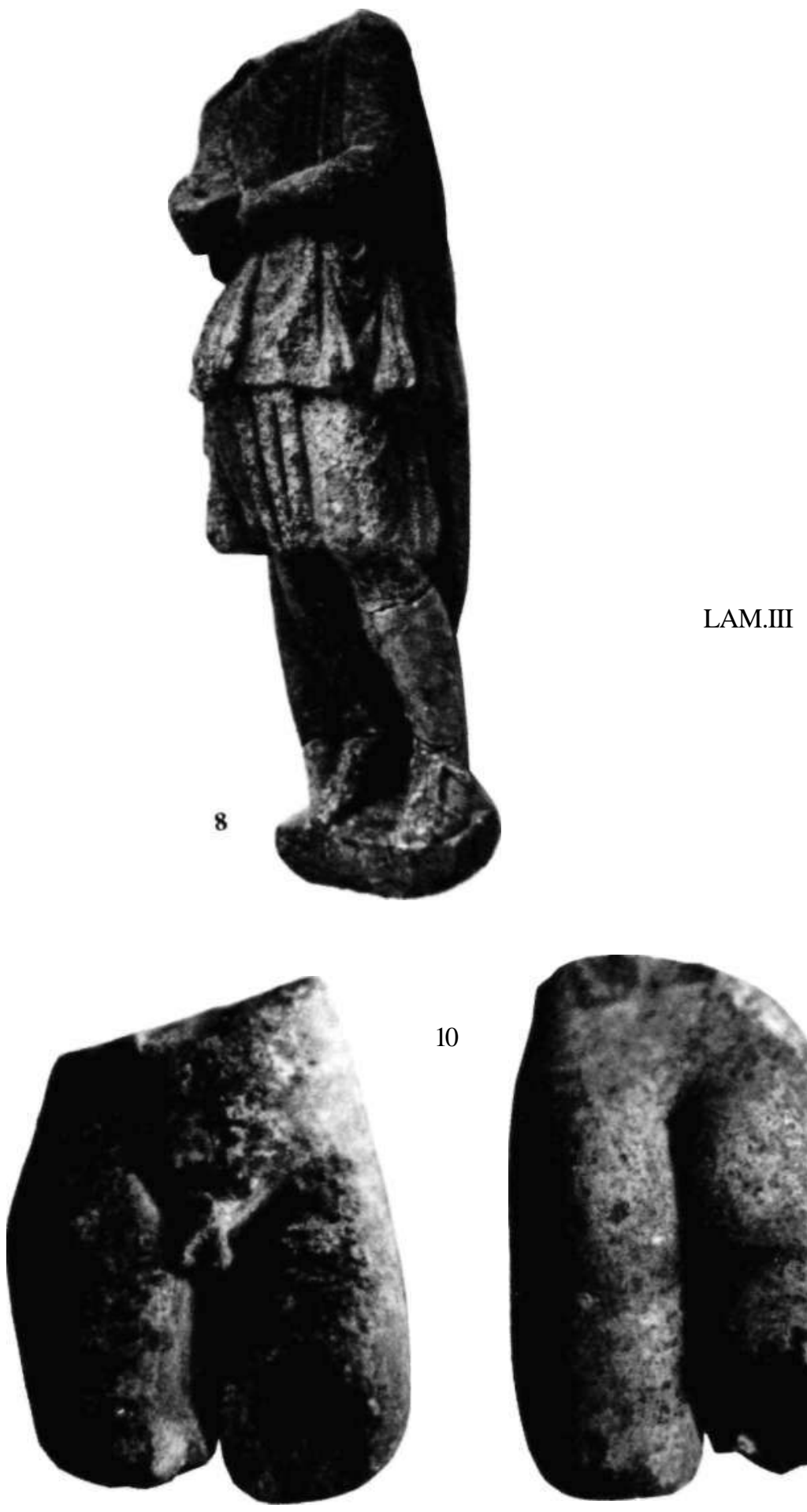

10

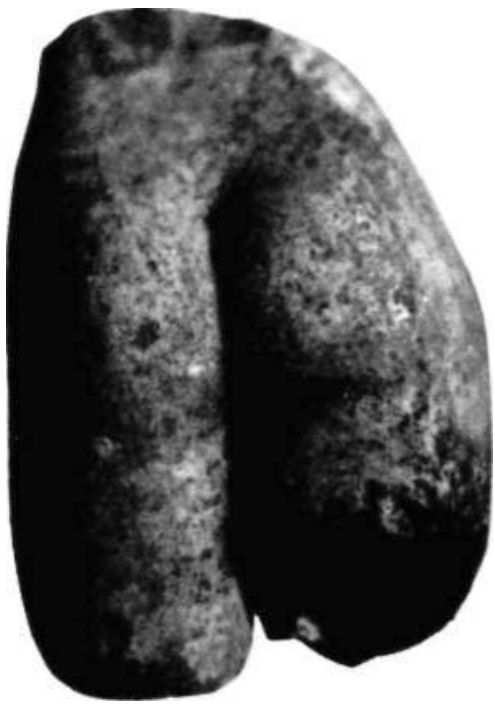



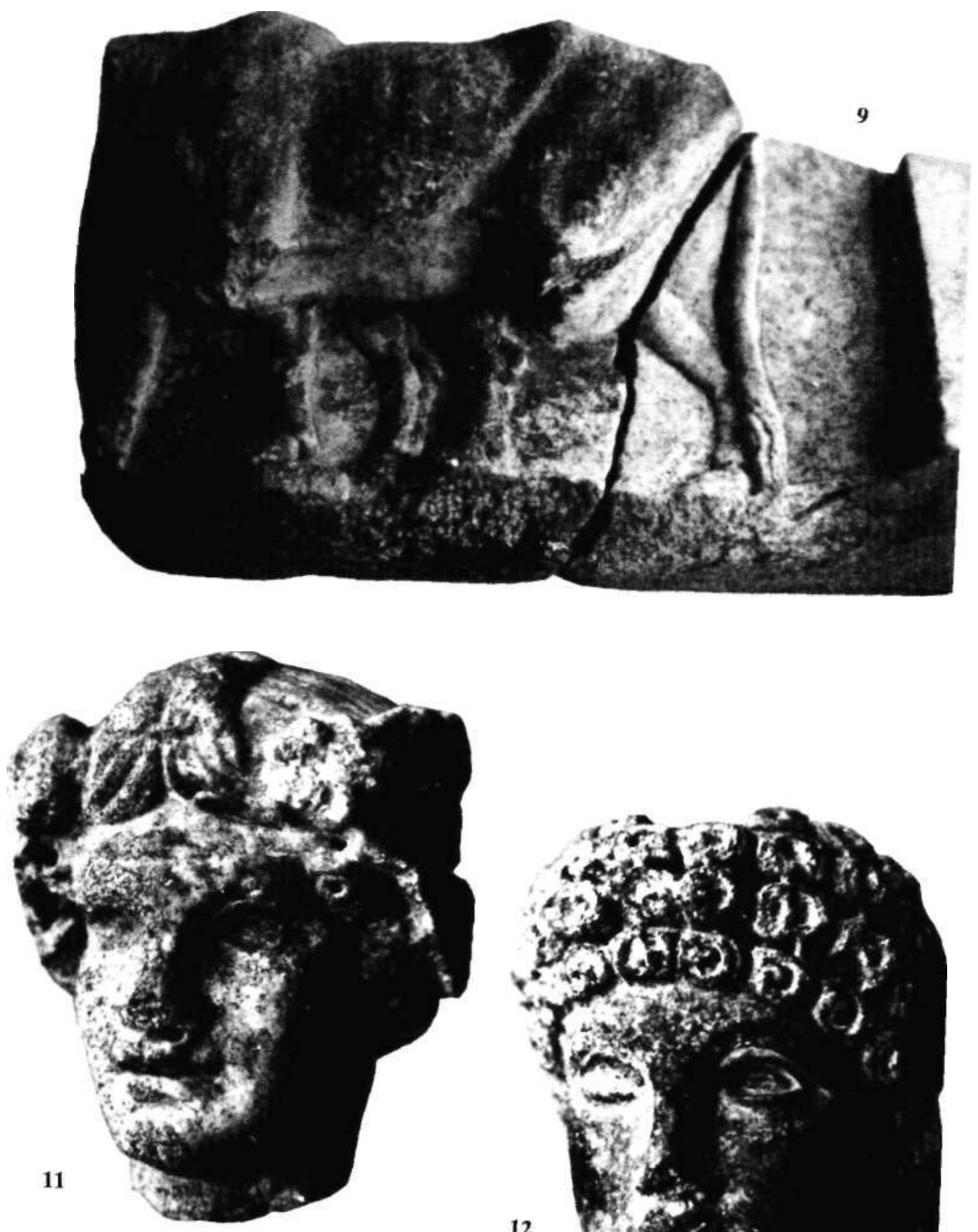

LAM. IV

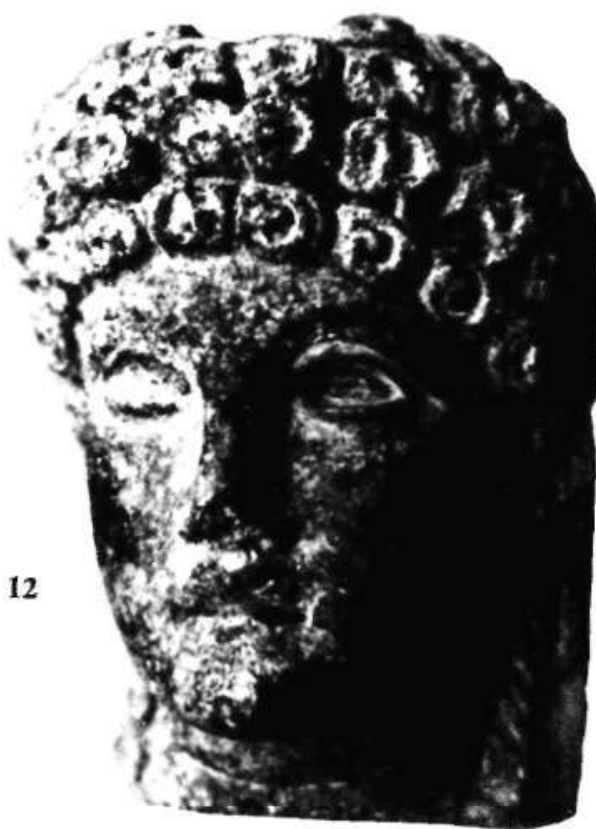




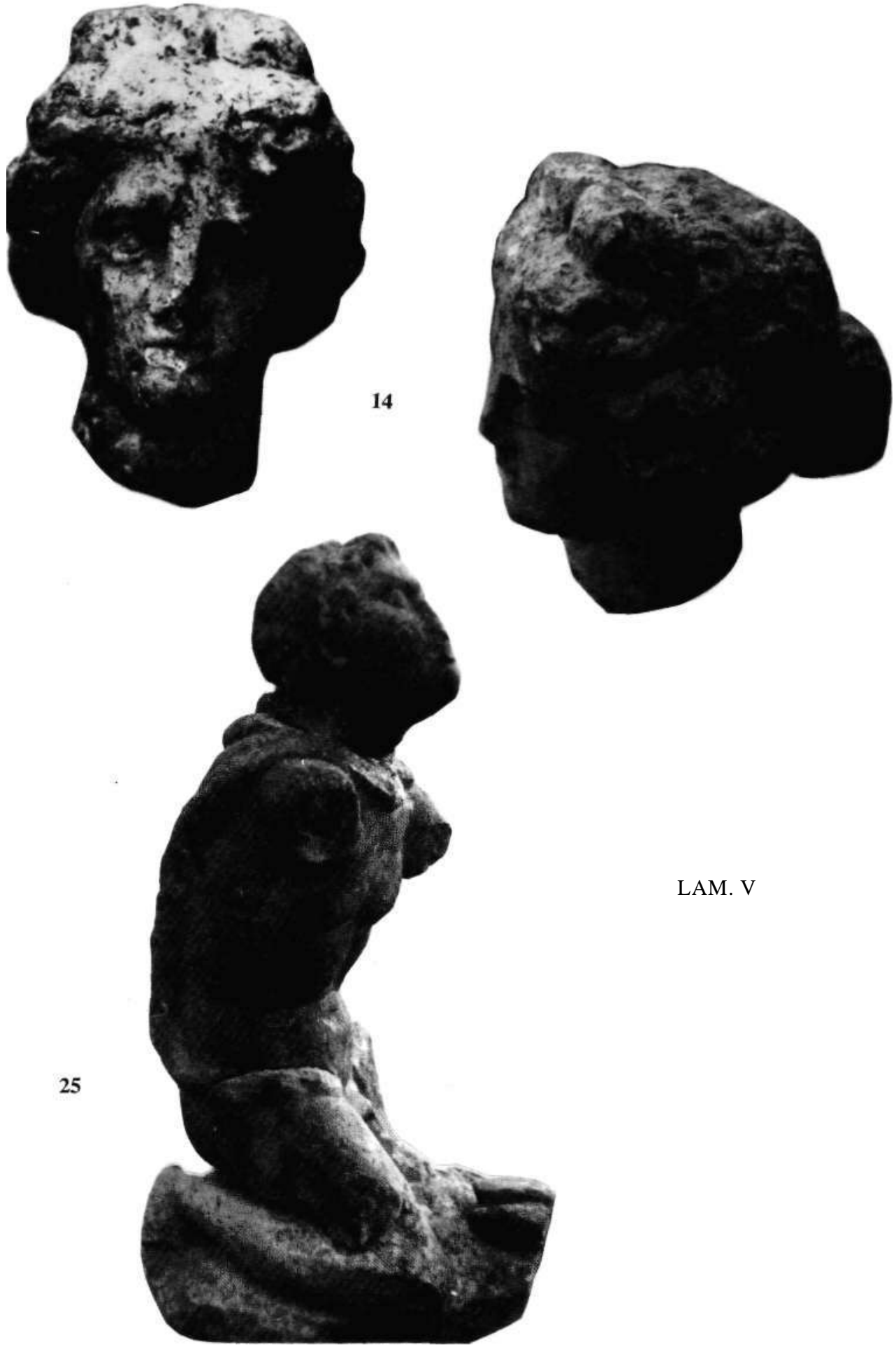

--- Grupo de investigación P.A.I. HUM 236 | http://www.arqueocordoba.com/publ/anales.htm --- 

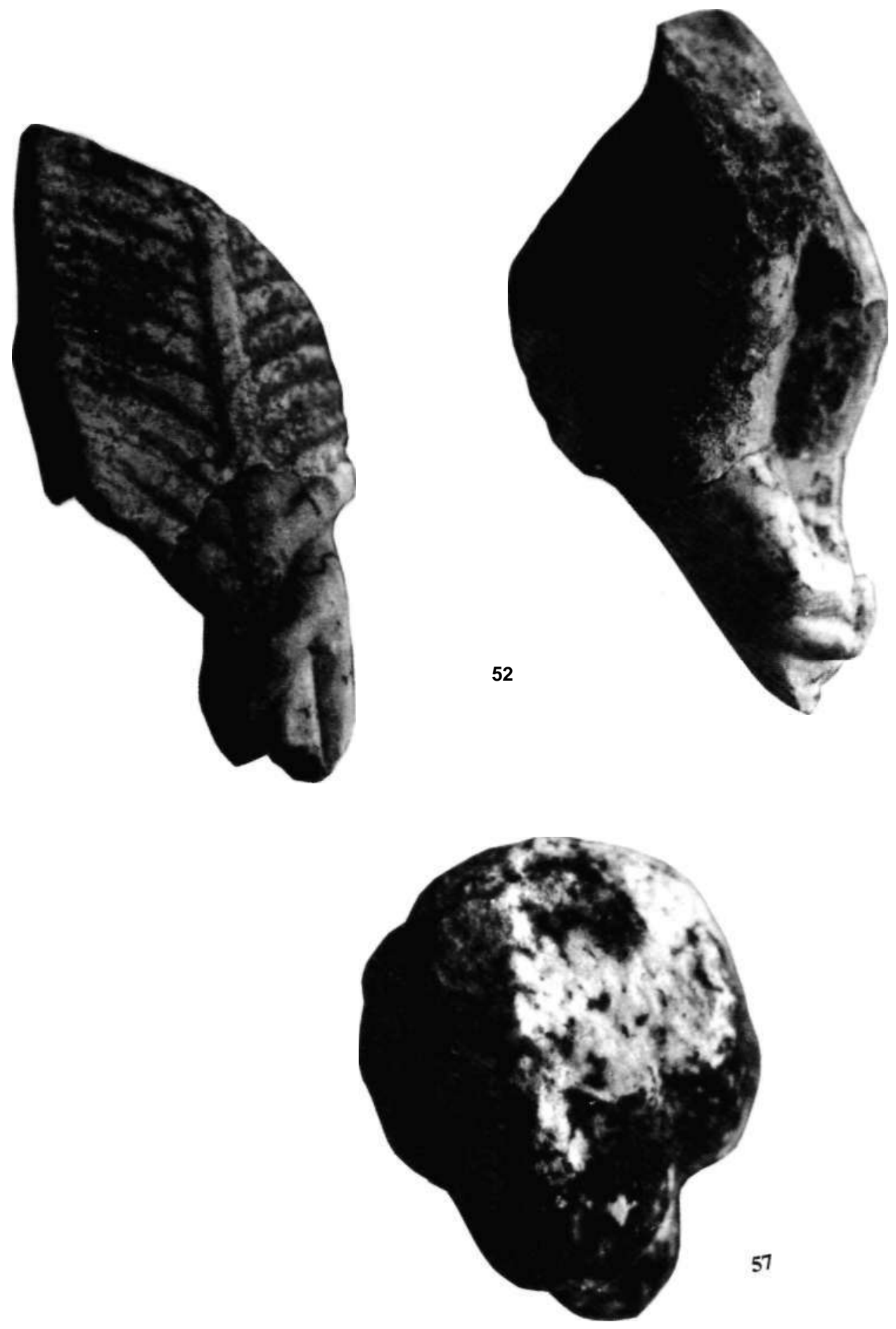

--- Grupo de InVII 


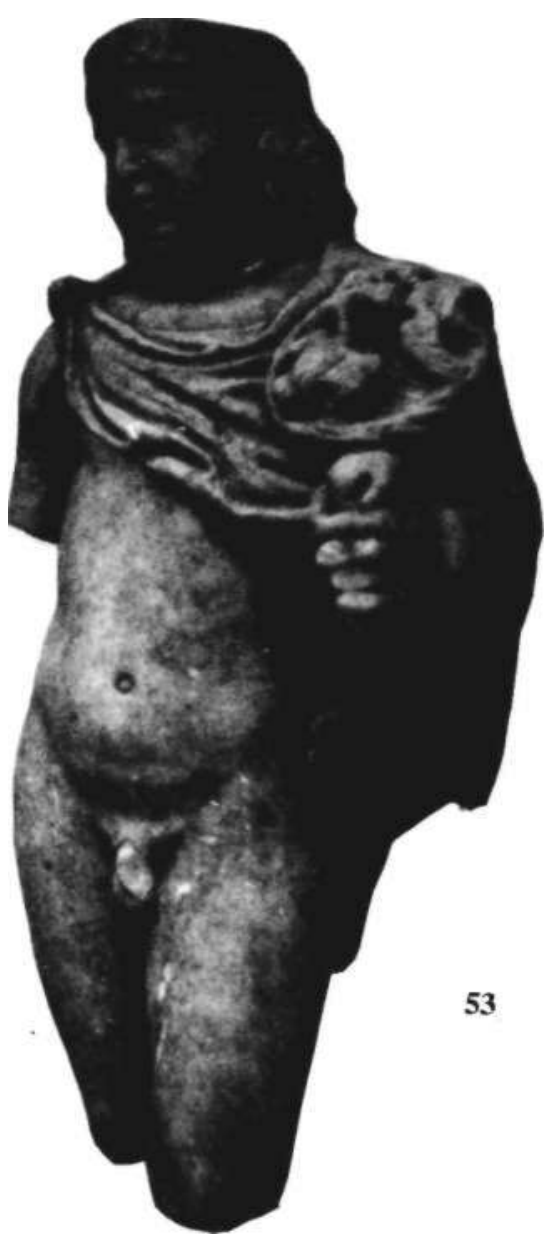

LAM. VII

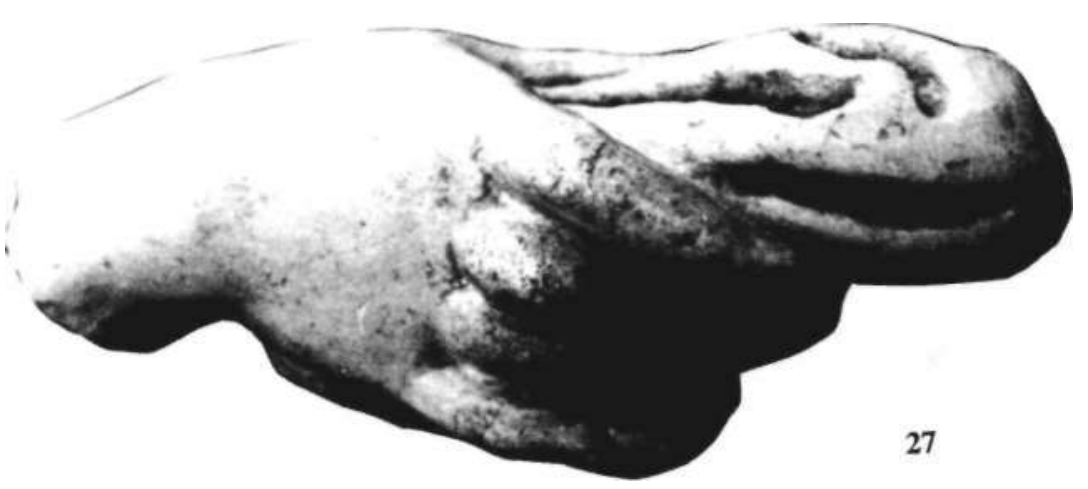

--- Grupo de investigación P.A.I. HUM 236 | http://www.arqueocordoba.com/publ/anales.htm --- 


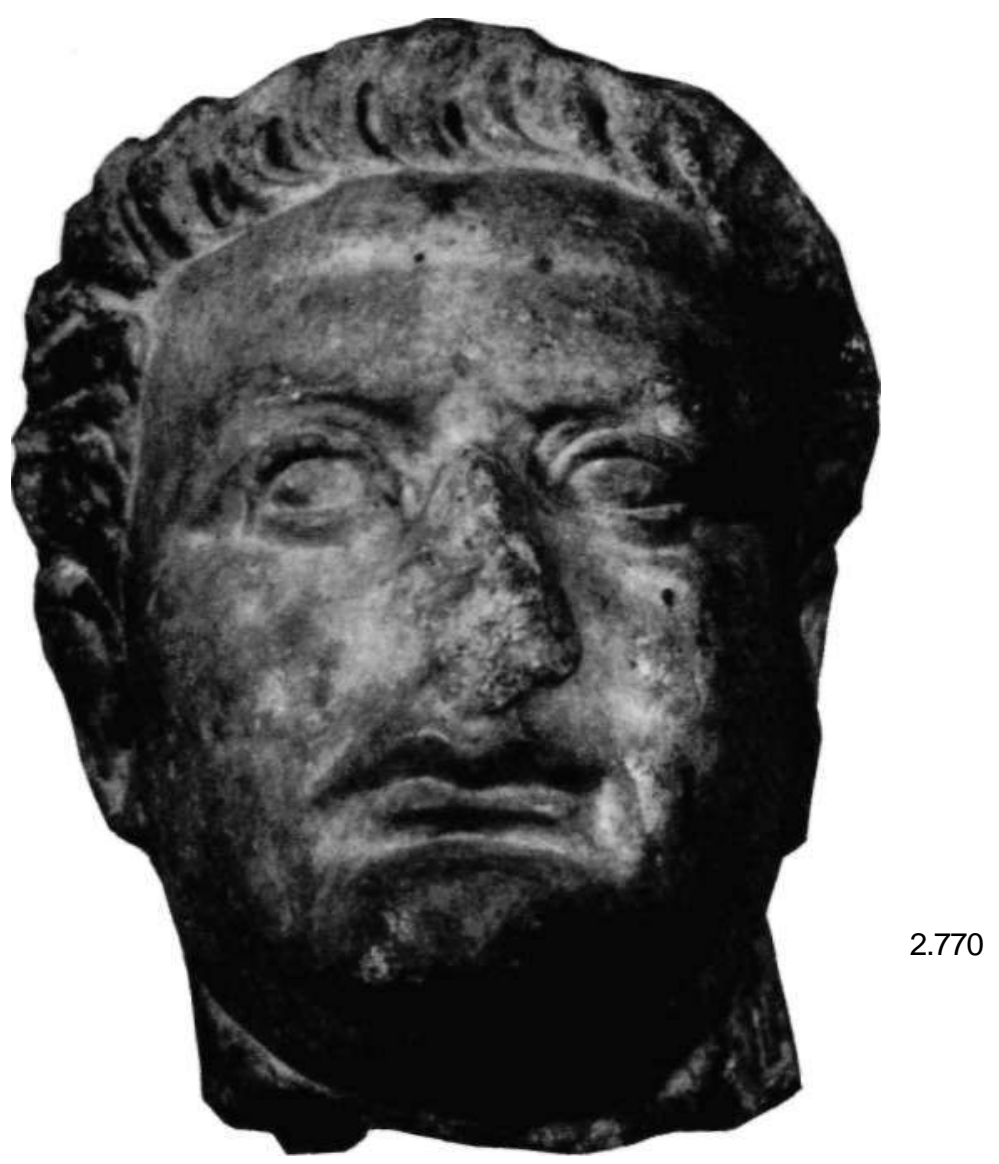

LAM.VIII

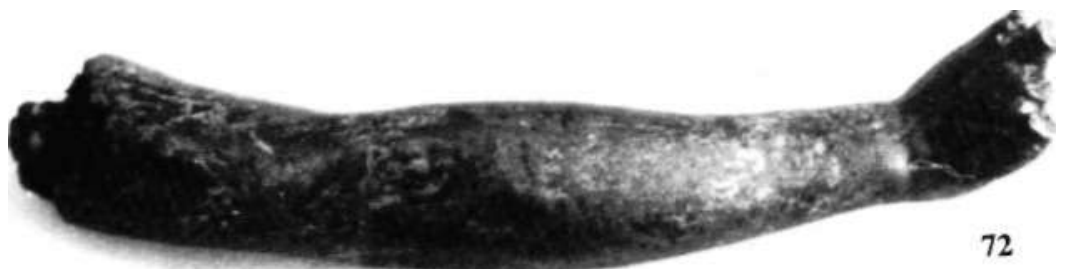

--- Grupo de investigación P.A.I. HUM 236 | http://www.arqueocordoba.com/publ/anales.htm --- 

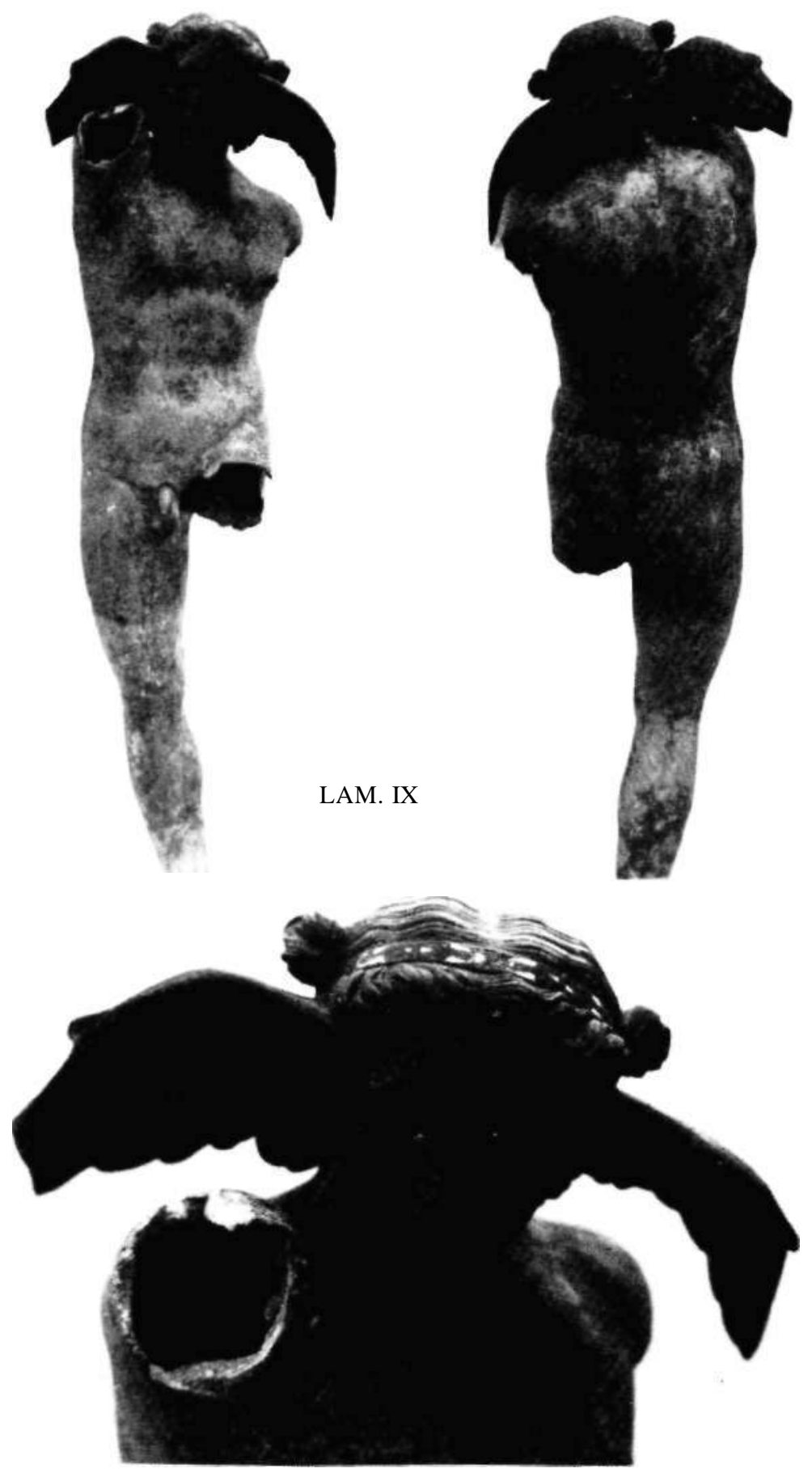

--- Grupo de investigación P.A.I. HUM 236 | http://www.arqueocordoba.com/publ/anales.htm --- 


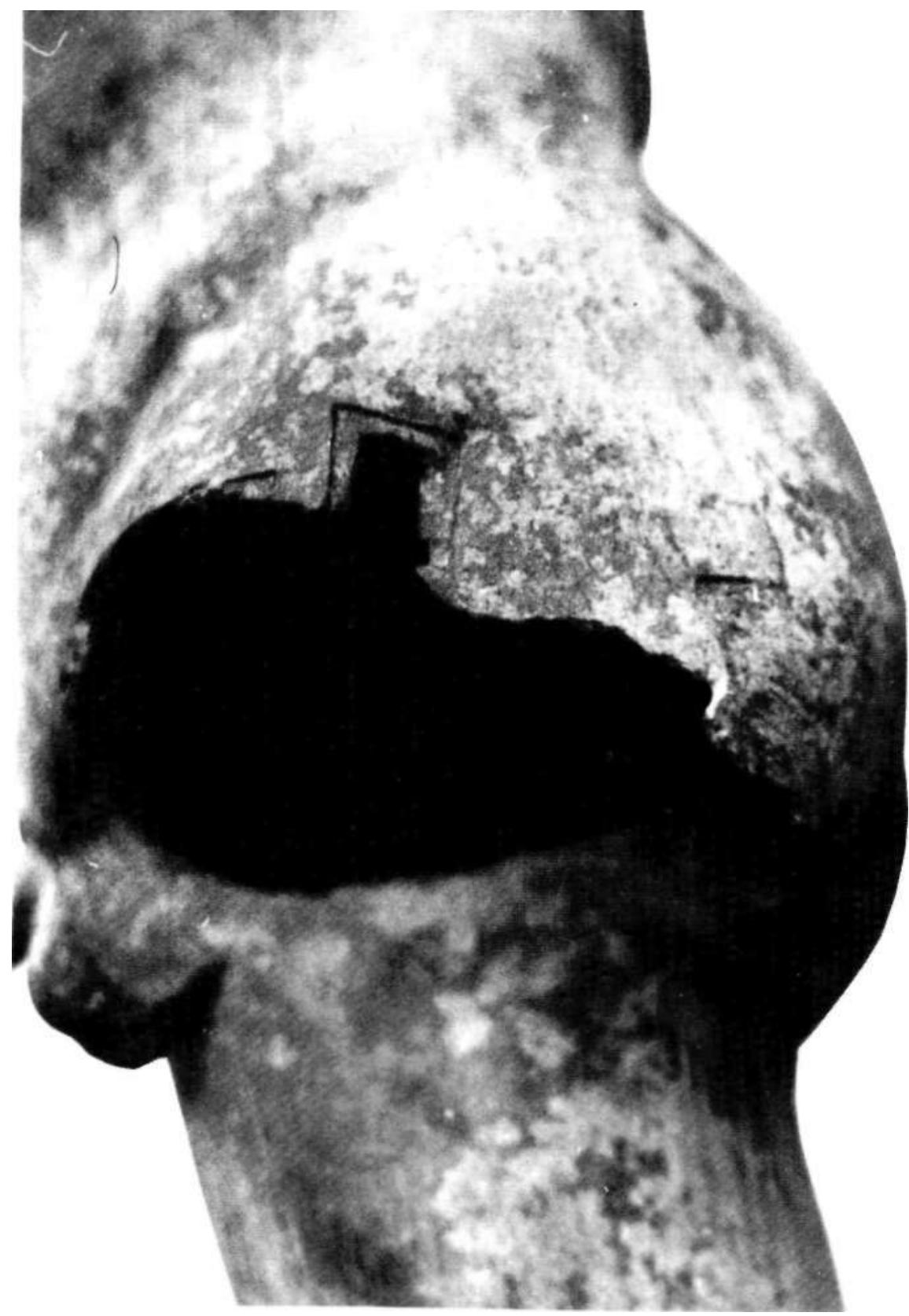

LAM. X

--- Grupo de investigación P.A.I. HUM 236 | http://www.arqueocordoba.com/publ/anales.htm --- 